SHORT REPORT

\title{
Testosterone measurements in early infancy
}

\author{
C Tomlinson, H Macintyre, C A Dorrian, S F Ahmed, A M Wallace
}

Arch Dis Child Fetal Neonatal Ed 2004;89:F558-F559. doi: 10.1136/adc.2003.034017

\begin{abstract}
Circulating testosterone concentrations in infants measured by a direct chemiluminescent immunoassay (Bayer ADVIA Centaur) were compared with those measured by a traditional radioimmunoassay using solvent extraction. The results confirm that neonatal circulating testosterone concentrations are method dependent, and each laboratory should establish method related reference ranges especially if using a direct commercial immunoassay. The results indicate that the Bayer ADVIA Centaur procedure can be used reliably in neonates. Expected values for male and female infants $<10$ days old were 2.5-11.1 ( $\mathrm{n}=36$ ) and 1.7-5.6 $(\mathrm{n}=36) \mathrm{nmol} / \mathrm{I}$ respectively. For older neonates (1050 days) the ranges were $0.2-17.2(n=42)$ and $0.1-1.5$ ( $\mathrm{n}=7$ ) $\mathrm{nmol} / \mathrm{l}$ respectively.
\end{abstract}

A lthough "direct" commercial steroid immunoassays are reliable in many clinical situations, concerns remain about their accuracy for steroid measurements in young infants. ${ }^{1}$ Determination of the plasma concentration of testosterone is an important part of the evaluation of infants with genital abnormalities. ${ }^{2}$ In affected infants with impalpable testes, the circulating testosterone concentration may indicate the presence of intra-abdominal testes and may also provide some clues about the underlying causes. The aim of this study was to compare neonatal circulating testosterone concentrations obtained by a recently developed and locally available commercial "direct" immunoassay (Bayer ADVIA Centaur) with those obtained with a traditional solvent extraction immunoassay. Despite reliable reference ranges for plasma testosterone assayed by extracted radioimmunoassay being described three decades ago, ${ }^{34}$ there is, rather surprisingly, a lack of more recent information. In addition to comparing the extracted assay with the more widely available direct assays, we have therefore also determined the reference range for plasma testosterone concentrations in young infants. This information should facilitate the management of the infant with genital anomalies.

\section{SUBJECTS AND METHODS}

Blood samples were obtained from a group of infants less than 6 months old having other investigations. Ethical approval was obtained from Yorkhill NHS Trust. Testosterone was measured directly by chemiluminescent immunoassay on the Bayer ADVIA Centaur analyser (sensitivity $0.35 \mathrm{nmol} /$ l, coefficient of variation $<7.6 \%$ ) and an in house radioimmunoassay with a preceding solvent extraction step (sensitivity $0.35 \mathrm{nmol} / \mathrm{l}$, coefficient of variation $<8 \%$ ).

Intergroup comparison was performed by the paired $t$ test using SPSS software.

\section{RESULTS}

Table 1 shows the median concentration and range of plasma testosterone as assayed by both the Centaur ADVIA direct immunoassay and the extraction radioimmunoassay in boys and girls less than 10 days old ( $\mathrm{n}=36$ and 36 respectively) and between 10 and 50 days old ( $\mathrm{n}=42$ and 7 respectively). The overall correlation between assays was good $(r=0.88$ : $\mathrm{n}=121$ ). In both boys and girls aged less than 10 days, significantly lower results $(\mathrm{p}<0.001)$ were obtained by the extraction radioimmunoassay. In boys $>10$ days, significantly lower results were obtained by the direct procedure $(\mathrm{p}<0.001)$.

Figure 1 shows the plasma testosterone concentrations measured by the extraction assay in boys and girls. In boys plasma testosterone concentrations are high at birth but rapidly fall over the first week before rising to a peak at 2 months of age. In girls, testosterone concentrations remain generally low over the first 6 months but could be as high as $5 \mathrm{nmol} / \mathrm{l}$ at birth.

\section{DISCUSSION}

Concern existed in the literature that commercial assays were inaccurate in the clinical setting of newborn infants when there are high levels of sulphated steroids. ${ }^{15}$ In fact, a spuriously raised testosterone concentration has occurred in our laboratory in a neonatal sample using the Bayer Immuno-l system, leading to diagnostic confusion. ${ }^{6}$ In addition, spuriously high adult female testosterone results are known to be produced by some automated analysers. $^{7}$

Fortunately, no spuriously raised results were obtained by the direct method used in this study. Although results from the two assays correlated well, there were significant differences in the values obtained. For neonates under 10 days of age, significantly lower testosterone concentrations were obtained by the in house extraction assay. This could be related to removal of cross reacting conjugated steroids by solvent extraction. For the older boys, significantly lower results were obtained by the direct assay, which is more difficult to explain. It is, however, clear that the direct assay was specifically developed for measuring testosterone in adults. The testosterone protein binding characteristics in neonatal samples are considerably different from that in adults, and this may affect the accuracy of the measurement. Further studies are required to clarify this issue.

Our results confirm that neonatal circulating testosterone concentrations are method dependent and each laboratory should establish method related reference ranges especially if using a direct commercial immunoassay. In addition to the ADVIA Centaur analyser used in this study, there are at least eight commercial non-radioactive immunoassays for testosterone. Each of these methods has been developed and optimised for measurement of testosterone in adults and should be viewed as suspect in relation to neonatal testosterone measurements unless proven otherwise.

Using the extracted assay, we studied circulating testosterone concentrations in detail in both sexes over the first 6 months of life. As previously reported in boys, ${ }^{3}$ the concentrations are in general very high at delivery showing a very wide variation, with almost a 10 -fold difference 

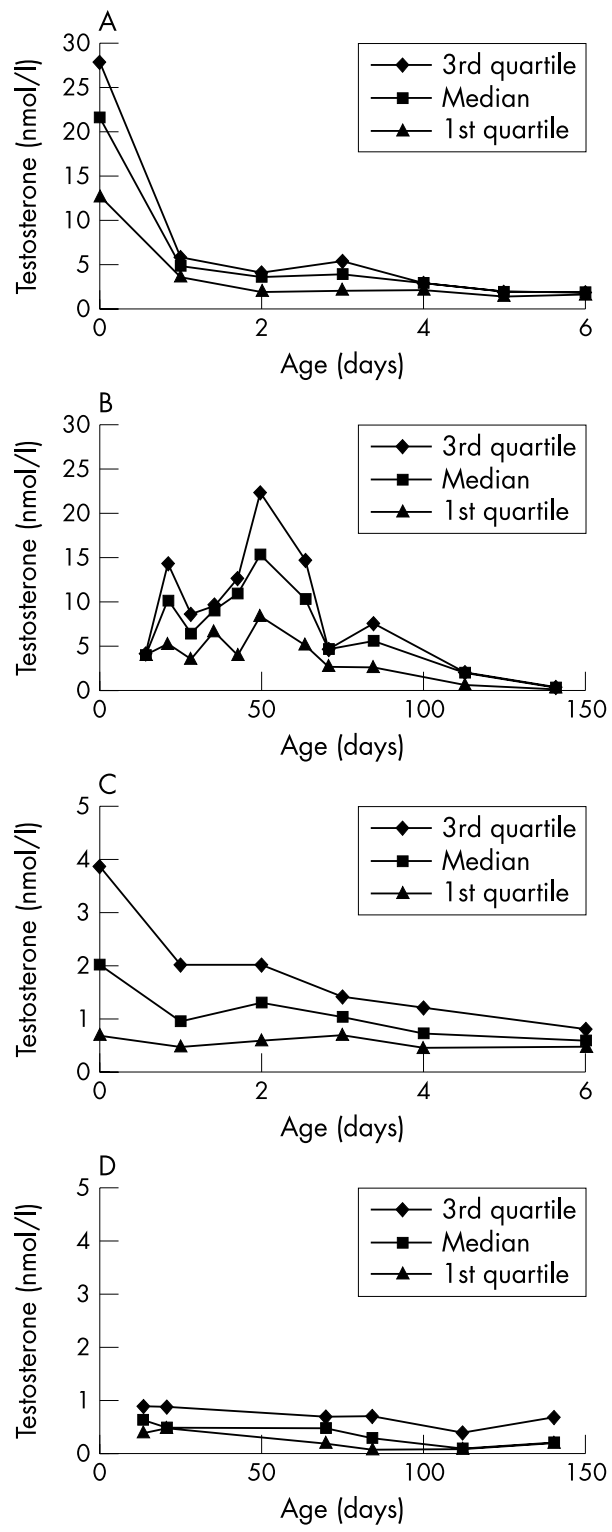

Figure 1 Change in plasma testosterone concentration with time in boys (A, B) and girls (C, D) measured by the extraction assay over the first week $(A, C)$, with samples grouped daily, and from 14 days to 6 months of life (B, D), with samples grouped weekly. The number of samples at each time point varied from 2 to 11 , median 5 .

between some infants. This concentration then falls very rapidly before a slow rise to a second peak at $\sim 2$ months and then falling to "normal" prepubertal concentrations by 6 months of age. Again there is a very wide variation, with a 10 -fold difference between some infants. In girls, there is a much smaller peak at delivery, which then falls to low
Table 1 Median and range of matched samples for testosterone assays by sex and age

\begin{tabular}{|c|c|c|c|c|c|c|}
\hline & \multirow[b]{2}{*}{$\mathbf{n}$} & \multicolumn{2}{|c|}{$\begin{array}{l}\text { In house } \\
\text { extraction assay }\end{array}$} & \multicolumn{2}{|c|}{$\begin{array}{l}\text { Bayer ADVIA } \\
\text { Centaur direct } \\
\text { assay }\end{array}$} & \multirow[b]{2}{*}{$p$ Value } \\
\hline & & Median & Range & Median & Range & \\
\hline \multicolumn{7}{|l|}{ Boys } \\
\hline$<10$ days & 36 & 2.3 & $1.0-11.5^{*}$ & 4.0 & $2.5-11.1^{*}$ & $<0.001$ \\
\hline$>10$ days & 42 & 4.6 & $0.3-29.3^{*}$ & 3.5 & $0.2-17.2^{*}$ & $<0.001$ \\
\hline \multicolumn{7}{|l|}{ Girls } \\
\hline$<10$ days & 36 & 0.7 & $0.3-3.6^{*}$ & 3.3 & $1.7-5.6^{*}$ & $<0.001$ \\
\hline$>10$ days & 7 & 0.5 & $0.2-1.3^{* *}$ & 0.8 & $0.1-1.5^{\star \star}$ & $\begin{array}{l}\text { Insufficient } \\
\text { data }\end{array}$ \\
\hline
\end{tabular}

Values are $\mathrm{nmol} / \mathrm{l}$.

*Reference range (within 95\% confidence intervals).

${ }^{* *}$ Absolute range (insufficient data to calculate $95 \%$ confidence intervals).

concentrations over the first week, which remain low over the next six months.

In conclusion, we have shown that there are small differences in measured testosterone concentrations in infancy between a commercial direct assay and one using an extraction step. These differences are, however, unlikely to cause problems in a clinical setting, and it would appear that the widely available Bayer ADVIA Centaur direct assay can be used reliably to measure testosterone in plasma from newborn infants.

\section{Authors' affiliations}

C Tomlinson, S F Ahmed, Bone \& Endocrine Research Group,

Department of Child Health, Royal Hospital For Sick Children, Yorkhill, Glasgow G3 8SJ, Scotland, UK

H Macintyre, C A Dorrian, A M Wallace, Department of Clinical Biochemistry, Glasgow Royal Infirmary, Glasgow G4 OSF

Correspondence to: Dr Wallace, Department of Clinical Biochemistry, Glasgow Royal Infirmary, Glasgow G4 OSF, Scotland, UK; MWallace@ gri-biochem.org.uk

Accepted 5 March 2004

\section{REFERENCES}

1 Fuqua JS, Sher ES, Migeon CJ, et al. Assay of plasma testosterone during the first six months of life: importance of chromatographic purification of steroids. Clin Chem 1995:41:1146-9.

2 Ahmed SF, Hughes IA. Management of ambiguous genitalia. Current Paediatrics 2000;10:269-74.

3 Forest MG, Sizonenko PC, Cathiard AM, et al. Hypophysogonadal function in humans during the first year of life. 1. Evidence for testicular activity in early infancy. J Clin Invest 1974;53:819-28.

4 Winter JS, Hughes IA, Reyes FI, et al. Pituitary-gonadal relations in infancy. 2. Patterns of serum gonadal steroid concentrations in man from birth to two years of age. J Clin Endocrinol Metab 1976:42:679-86.

5 Wallace AM, Beesley J, Thomson M, et al. Adrenal status during the first month of life in mature and premature human infants. J Endocrinol 1997; 1 12:473-480.

6 Tomlinson C, Wallace AM, Ahmed SF. Erroneous testosterone assay causing diagnostic confusion in a newborn infant with intersex anomalies. Acta Paediatrica 2004;93:1-2.

7 Herold DA, Fitzgerald RL. Immunoassays for testosterone in women: better than a guess. Clin Chem 2003;49:1250-1. 